\title{
ESTETIKA PROFETIK AHMAD TOHARI DALAM KHAZANAH BUDAYA CABLAKA
}

\author{
Teguh Trianton \\ Universitas Muhammadiyah Purwokerto \\ Jl. Raya Dukuhwaluh PO BOX 202 Purwokerto, 53182 \\ E-mail: teguh3anton@yahoo.com \\ HP. +62-8156987444
}

Abstract: This article describes the prophetic aesthetic representation in Banyumas culture which is known as cablaka. The data are taken from literature review of short stories entitled Senyum Karyamin by Ahmad Tohari. The work is based on the writer's background as a cultural observer, and pesantren owner. Hermeunetic approach is applied in this research. Overall the prophetic aesthetic is represented in four characters; cablaka, sabar lan nrima, berjiwa ksatria, dan cancudan. There are three concepts of prophetic aesthetic; humanism (amar ma'rüf), liberation (nahi munkar) and transcendence (faith to God, tu'minuna billah).

Abstrak: Tulisan ini berupaya mendeskripsikan tentang representasi estetika profetik dalam khazanah budaya Banyumas yang dikenal cablaka. Data diambil melalui prosedur studi pustaka pada buku kumpulan cerpen Senyum Karyamin karya Ahmad Tohari. Pengarang merupakan sastrawan, budayawan dan pengasuh pondok pesantren, sehingga karya-karyanya menjadi presentasi latar sosial dan inteletualnya, lantaran sastra tidak pernah ditulis dalam situasi kosong budaya. Analisis dan pembahasan dilakukan dengan pendekatan hermeneutika yang medasarkan pada caracara menafsir teks agama Islam. Secara keseluruhan buku cerpen ini menunjukan estetika profetis dalam satu kesatuan yang utuh (simultanitas) antara empat karakter; cablaka, sabar lan nrima, berjiwa ksatria, dan cancudan dengan tiga konsep estetika profetik, yaitu humanisasi (amar ma’rūf), liberasi (nahi munkar), dan transendensi yaitu beriman kepada Allah SWT (tu'minuna billah).

Kata Kunci: Estetika, Sastra Profetik, Budaya, Cablaka, Masyarakat. 


\section{A. Pendahuluan}

Estetika pada mulanya merupakan cabang filsafat yang menelaah dan membahas tentang seni dan keindahan serta tanggapan manusia terhadapnya. Estetika secara leksikal dimaknai sebagai kepekaan terhaadap seni dan keindahan (KBI, 2008: 401). Pada perkembangan, penggunaan lema estetika melahirkan terminologi estetis yang berarti indah dan berkenaan dengan keindahan. Keindahan adalah nilai yang diberikan pada sesuatu yang dianggap mengandung unsur seni. Lantas, yang dimaksud estetika dalam tulisan ini adalah segala hal yang berkenaan dengan nilai keindahan bahasa dalam karya sastra.

Sastra merupakan produk seni, maka sastra yang baik adalah sastra mampu mencapai nilai estetika tertinggi. Namun bagi Kuntowijoyo sastra yang baik adalah sastra yang mampu menterjemahkan tiga peran tersebut dalam rangka menjalankan misi profetik. Di sinilah, sastra ditulis sebagai mode komunikasi yang inten yang berupaya memahamkan pembaca tentang pentingnya melakukan amar ma'rūf (humanisasi), nahi munkar (liberasi) dan tu'minu billāh (transendensi). Bertemunya misi dakwah -peran kenabian- dengan sastra inilah yang melahirkan terminologi sastra profetik, yaitu sastra yang mengandung nilai-nilai profetik.

Hal inilah yang menjadi vitalitas dan dasar dari semangat Ahmad Tohari dalam melakukan proses kreatif menulis sastra, termasuk cerpen-cerpennya yang termaktub dalam kumpulan cerpen Senyum Karyamin (Tohari, 2005). Kapasitas Ahmad Tohari dalam panggung sastra Indonesia tak perlu diragukan lagi. Penulis novel trilogi Ronggeng Dukuh Paruk (RDP) ini telah menjadi salah satu kampium sastrawan dunia dari Indonesia. Namanya mulai melambung, tatkala pada dekade 1970-an cerpen berjudul "Jasa-jasa Buat Sanwirya" mendapat anugerah Sayembara Kincir Emas Radio Nederland Wereldomroep (1975). Tahun 1989, cerpen ini, dibukukan bersama 12 cerpen lain dalam buku kumpulan cerpen Seyum Karyamin (SK).

Di sisi lain, kumpulan cerpen SK merupakan potret kehidupan wong Banyumas yang apa adanya (cablaka). Karakter cablaka menjadi pusat atau inti model dari keseluruhan karakter wong Banyumas. Cablaka dapat dimaknai sebagai karakter yang mengedepankan keterusterangan ala wong Banyumas. Jika bertut ur kata selalu thokmelong (tanpa basa-basi), sehingga dari luar akan tampak tidak memiliki unggah-ungguh (etika), lugas, dan terkesan kurang ajar (Priyadi, 2007: 13). Cablaka dan sikap egaliter merupakan identitas budaya wong Banyumas (Trianton, 2013: 18). 
Persinggungan latar sosial budaya Banyumas yang cablaka dengan pengetahuan Islam dan tradisi pesantren menjadikan karya Tohari penuh dengan nilai profetik dalam simpul khazanah budaya cablaka. Estetika cerpen-cerpen Tohari juga didukung dengan diksi bahasa Banyumasan dipadu dengan bahasa Indonesia yang sederhana dan lugas sehingga maksud pesan mudah dimengerti. Di sinilah pentingnya tulisan ini; secara khusus berupaya mengidentifikasi dan membahas ihwal estetika profetik dalam khazanah budaya cablaka yang terpresentasi pada kumpulan cerpen Senyum Karyamin karya Ahmad Tohari. Tulisan ini secara keseluruhan merupakan interpretasi terhadap teks sastra menggunakan pendekatan hermeneutika.

\section{B. Etika dan Kaidah Sastra Profetik}

Etika adalah kumpulan asas atau nilai yang berkenaan dengan akhlak. Etika juga dapat berarti asas yang mendasari perilaku sehingga dapat menjadi pedoman (KBI, 2008: 402). Kemudian, terminologi profetik berasal dari bahasa Inggris, Prophet yaitu nabi. Terminologi ini juga berasal dari bahasa Yunani 'prophetes' (Roqib, 2011: 46). Profetik juga diartikan sebagai suatu yang berkenaan dengan nabi atau kenabian. Etika dalam konteks sastra profetik adalah etika profetik. Etika itu disebut "profetik" karena ingin meniru perbuatan nabi (Kuntowijoyo, 2013: 16). Dengan demikian, etika profetik adalah asas yang menjadi pedoman bagi seseorang untuk melakukan tindakan meniru perbuat an kenabian. Oleh karena itu, etika sastra profetik adalah asas yang menjadi pondasi bagi sastrawan dalam menulis sastra yang mengemban misi kenabian.

Etika sastra profetik bersumber pada Q.S.3:110, yang di dalamnya menjelaskan bahwa "kamu adalah umat terbaik yang dilahirkan untuk manusia menyeruh kepada yang ma'rūf (kebaikan) dan mencegah dari yang munkar (kejahatan), serta beriman kepada Allah $S W T$ ". Ayat tersebut oleh Kuntowijoyo dijadikan tiang utama konstruksi sastra profetik. Ayat ini kemudian diejawantahkan dalam tiga konsep etika profetik, yaitu humanisasi (amar ma'rüf), liberasi (nahi munkar) dan transendensi yaitu beriman kepada Allah SWT ( tu'minūna billāh).

Sebenarnya, etika profetik Kuntowijoyo berakar pada etika kenabiaan yang digagas Muhammad Iqbal. Ia memaknai etika kenabian (profetik) sebagai etika transformatif. Nabi bukanlah seorang mistikus. Nabi adalah seorang manusia pilihan yang sadar sepenuhnya dengan tanggung jawab sosial. Sehebat apapun pengalaman spiritual yang dijalaninya, seorang nabi tidak pernah terlena. Ia kembali memasuki lintasan ruang dan waktu sejarah, hidup dalam realitas sosial kemanusiaan untuk melakukan kerja-kerja transformatif. Seorang 
nabi datang dengan membawa cita-cita perubahan dan semangat revolusioner (Iqbal, 1996: 145).

Adapun yang menjadi puncak pencapaian estetika karya sastra (profetik) adalah tatkala sastra mampu mempertemukan kebenaran dan religiositas dengan keindahan (Noor, 2011: 82). Artinya, sebuah karya sastra yang baik adalah karya yang mampu mengemas religiositas secara indah kepada pembacanya. Pada mulanya, segala sastra adalah religius (Mangunwijaya, 1988). Religiositas juga mencakup persoalan rindu, perasaan ingin selalu bersama dengan sesuatu yang abstrak, yang berada di luar jangkauan pikiran dan hati, yang kendati pun abstrak tetapi keberadaannya sangat riil (Noor, 2011:83).

Sebelum merumuskan etika profetik, Kuntowijoyo juga merumuskan kaidah sastra profetik. Sastra profetik mempunyai kaidah-kaidah yang memberi dasar kegiataannya, sebab ia tidak hanya menyerap dan mengekspresikanya, tapi juga memberi arah realitas. Sastra profetik adalah sastra dialektik, maksudnya sastra yang berhadapan dengan realitas, melakukan penilaian dan kritik sosial budaya secara beradab. Menurut Kuntowijoyo (2006: 1-2), sastra profetik adalah sastra yang terlibat dalam sejarah kemanusiaan, ia bukan sastra yang terpencil dari realitas kehidupan. Sastra profetik juga merupakan sastra yang demokrasi, ia tidak otoriter dengan memilih satu premis, tema, teknik, dan gaya (style). Keinginan sastra profetik hanya sebatas bidang etika, itupun dengan sukarela tidak memaksa (Kuntowijoyo, 2006: 8).

Dialektika dalam sastra profetik menyatukan dua dimensi penting dari kehidupan manusia, yaitu dimensi sosial dan dimensi transendental. Inilah yang tujuan dari sastra religius. Religius berakar pada kata religi dan religio (Bahasa Latin) yang berarti perasaan keagamaan (Wachid, B.S., 2002: 176). Perasaan keagamaan ini merupakan segala bentuk perasaan batin yang berhubungan dengan Tuhan, seperti; takut, dosa dan kekaguman pada kebesaran Tuhan. Religiositas harus didasari dengan niat berbuat kebaikan kepada sesama. Dengan demikian, sastra religius adalah sastra yang mempersoalkan dimensi kemanusiaan dalam kaitanya dengan dimensi transendental (Wachid, B.S., 2002: 177). Dialektika semacam ini mengembalikan seni (sastra) berdekatan dengan agama, dengan kembalinya seni mendekat pada agama, maka seni mampu kembali membawa pesan moral dan filosofi profetik (Hadi W.M, 2004: 12).

Sesungguhnya, melalui kaidah sastra profetik, Kuntowijoyo ingin mengintegrasikan prinsip ḥabl min Allāh (hubungan manusia dengan Tuhan/ transedensi) dan habl min al-nās (hubungan manusia dengan sesamanya) dalam teks sastra. Sastra profetik memiliki nilai strategis untuk melakukan hubungan 
transenden (vertikal) sekaligus hubungan sosial (horizontal). Sastra profetik mempunyai kaidah-kaidah yang memberi dasar kegiatannya, sebab ia tidak saja menyerap, mengekspresikan, tapi juga memberi arah realitas. Kaidah-kaidah sastra profetik meliputi: (1) epistemologi strukt uralisme transendental, (2) sastra sebagai ibadah, dan (3) keterkaitan antar kesadaran (Kuntowijoyo, 2013: 1014).

Pertama, sastra profetik bermaksud melampaui keterbatasan akal pikiran manusia dan mencapai pengetahuan yang lebih tinggi. Sastra profetik ditulis dengan mengambil pemahaman dan penafsiran terhadap teks kitab suci atas realitas, kemudian memilih epistemologi strukturalisme transendental.

Kedua, sastra sebagai ibadah maksudnya bahwa proses kreatif bersastra berpijak pada ajaran Islam. Sastra ibadah ditulis dengan gaya bertutur dakwah. Gaya bertut ur semacam ini membuat sastra jauh dari perenungan. Dalam perspektif Kuntowijoyo, konsep sastra ibadah tidak berhenti pada tingkat tutur dakwah, namun ia tetap berada pada posisi sebagai sastra yang murni (Anwar, 2007: 154). Kuntowijoyo mengungkapkan; bahwa yang dimaksud sastra ibadah adalah ekspresi dari penghayatan nilai-nilai agama. Sastra murni adalah ekspresi dari tangkapan at as realitas,"objektif" dan universal. Sastra ibadah sama dan sebangun dengan sastra murni. Sastra ibadah adalah sastra tidak kurang tidak lebih (Anwar 2007: 155).

Ketiga, keterkaitan antarkesadaran ketuhanan dan kesadaran kemanusiaan. Kesadaran ketuhanan adalah setiap perilaku yang mencerminkan dan dilandasi nilai transendensi; hubungan hamba dengan Tuhan. Kesadaran kemanusiaan merupakan kesadaran tentang pentingnya hubungan manusia dengan sesamanya sebagai makhluk sosial yang setara. Kedua kesadaran tersebut harus berjalan simultan; ḥabl min Allāh wa ḥabl min al-nās. Bobot keduanya harus berimbang, tidak boleh ada yang diunggulkan. Islam melarang kesadaran ketuhanan dalam laku sufisme ekstrem, dan uzlah (mengasingkan diri), wadat (tidak kawin), dan kerahiban. Sebaliknya, perjuangan unt uk manusia (kemerdekaan, demokrasi, HAM) juga harus memperhatikan hak-hak Tuhan (Kuntowijoyo, 2013: 15).

\section{Estetika Budaya Cablaka}

Estetika adalah bagian dari filsafat. Estetika dikelompokkan dalam persoalan nilai, atau filsafat tentang nilai, dan sejajar dengan nilai etika. Berdasar objeknya, estetika dikelompokkan dalam bahasan filsafat manusia, yang terdiri dari logika, etika, estetika, dan antropologis. Studi estetika sebagai filsafat yang bersifat spekulatif, mendasar menyeluruh dan logis ini, pada mulanya me- 
rupakan bagian pemikiran filsafat umum seorang filosof. Akhirnya, yang menjadi fokus filsafat keindahan adalah karya-karya seni. Dengan demikian, tujuan estetika adalah keindahan, sedang tujuan logika adalah kebenaran. Keindahan seni karena punya makna dan dapat membawa nilai-nilai lain di samping nilai keindahan (Sumardjo, 1983: 25-26).

Kebudayaan adalah keseluruhan sistem gagasan, tindakan dan hasil karya manusia dalam rangka kehidupan masyarakat yang dijadikan milik diri manusia dengan belajar (Koentjaraningrat, 2004: 72). Rumusan ini menunjukkan eratnya hubungan budaya dengan manusia. Kebudayaan menjadi sesuatu yang dapat memengaruhi tingkat pengetahuan masyarakat. Sebelum mewujud sebagai materi, kebudayaan mengendap di ranah kognitif sebagai bagian dari sistem ide atau gagasan.

Kebudayaan itu sendiri mewujud dalam tiga bentuk. Pertama, kebudayaan sebagai suatu yang kompleks dari ide, gagasan, nilai-nilai, norma-norma dan perat uran. Wujud kebudayaan ini bersifat abstrak, tak dapat diraba, lantaran berupa konsep seperti adat-istiadat termasuk tatacara atau bagaimana orang berbicara. Kedua, kebudayaan sebagai suatu yang kompleks dalam aktivitas atau tindakan berpola dari individu dalam masyarakat. Inilah yang disebut sistem sosial, yang terdiri dari aktivitas manusia yang saling berinteraksi, berhubungan sehingga membentuk suatu tindakan bersistem. Ketiga, kebudayaan sebagai benda-benda hasil karya manusia, disebut juga sebagai kebudayaan bendawi (Koentjaraningrat, 2004: 5).

Masyarakat di wilayah Banyumas dalam konteks komunitas budaya Jawa disebut "wong Banyumas" (Herusatoto, 2008: 6). Entitas sosial memiliki identitas yang berbeda dengan komunitas lainnya, seperti wong Sala, wong Yogya, wong Semarang atau wong Surabaya. Perbedaan ini terletak pada logat bahasa Jawa yang digunakan dalam peristiwa tutur. Selain logat yang disebut ngapak, wong Banyumas juga memiliki bahasa sendiri yaitu bahasa Banyumas.

Bahasa dan dialek Banyumas ini merepresentasikan karakter atau watak asli wong Banyumas, yaitu; (1) cablaka; (2) sabar lan nrima; (3) berjiwa ksatria; dan (4) cancudan (Trianton, 2013: 16). Karakter cablaka at au blakasuta adalah pusat atau menjadi inti model dari keseluruhan karakter wong Banyumas. Cablaka adalah perwujudan karakter yang mengedepankan keterusterangan manusia Banyumas. Jika bertut ur kata selalu thokmelong (tanpa basa-basi) sehingga dari luar akan tampak tidak memiliki unggah-ungguh (etika), lugas, dan terkesan kurang ajar (Priyadi, 2007: 13).

Dengan demikian, estetika budaya cablaka merupakan konstruksi estetik yang dibangun dengan pondasi karakter asli wong Banyumas yang cablaka, 
sabar lan nrima, berjiwa ksatria dan cancudan. Estetika ini menjadi ideologi kaum penginyongan dalam melakoni kehidupan sehari-hari. Estetika cablaka menjadi dasar perwujudan ḥabl min Allāh wa ḥabl min al-nās yang merupakan ide pokok estetika profetik.

\section{Profetisitas Estetika Cablaka pada Cerpen}

Profetisitas dalam estetika khazanah budaya cablaka terbentuk dari karakter (1) cablaka; (2) sabar lan nrima; (3) berjiwa ksatria; dan (4) cancudan. Keempat khazanah budaya Banyumas ini secara simultan merepresentasikan kaidah profetik, yaitu tiga konsep estetika profetik: humanisasi (amar ma'rüf), liberasi (nahy munkar) dan transendensi dengan beriman kepada Allah SWT (tu'minūna billāh).

\section{Cablaka}

Cablaka ialah sikap terbuka secara lahir dan batin dengan pertimbangan yang matang dari apa yang diucapkan secara spontan dengan bahasa yang lugas, tegas, dan tanpa tedeng aling-aling atau eufemisme. Cablaka membentuk pola hubungan antarsesama masyarakat Banyumas berlangsung egaliter. Perasaan dalam kebersamaan dan kesetaraan hubungan antarmanusia yang saling nguwongake (memanusiakan) ini, antara lain terepresentasi pada keseluruhan cerpen dalam kumpulan cerpen SK.

"Sudah, Min. Pulanglah. Kukira hatimu tertinggal di rumah sehingga kamu loyo terus," kata Sarji yang diam-diam iri dengan istri Karyamin yang muda dan gemuk.

"Memang bahaya meninggalkan istrimu seorang diri di rumah. Min, kamu ingat anak-anak muda petugas bank harian itu? Jangan kira mereka hanya datang setiap hari buat menagih setoran kepada istrimu. Jangan percaya kepada anak-anak muda penjual duit itu. Pulanglah. Istrimu kini pasti sedang digodanya."

"Istrimu tidak hanya menarik mata petugas bank harian. Jangan dilupa tukang edar kupon buntut itu. Kudengar dia juga sering datang ke rumahmu bila kamu sedang keluar. Apa kamu juga percaya dia datang hanya untuk menjual kupon buntut? Jangan-jangan dia menjual buntutnya sendiri!” (Tohari, 1989: 2).

Tuturan cablaka yang blakasuta atau thokmelong merupakan karakter orang Banyumas, yang mengedepankan keterusterangan. Tuturan thokmelong (tanpa basa-basi) dari luar akan tampak kurang unggah-ungguh (etika), lugas dan terkesan kurang ajar. Sarji berterus-terang mengatakan apa adanya hal yang sebenarnya dapat menyinggung perasaan Karyamin. Akan tetapi, bagi wong 
Banyumas, seloroh-seloroh seperti itu tidak akan menimbulkan ketersinggungan atau sakit hati. Di sisi lain, tuturan cablaka merepresentasikan humanisme; simpati dan empati. Tuturan seperti ini sering kali lebih mengharukan ketimbang ungkapan eufimisme. Daya ungkap cablaka atas apa yang menimpa sesamanya akan membuat hati nggrentes (seperti tersayat).

"Tidak. Kalau kamu tak tahan melihat aku lapar, aku pun tak tega melihat daganganmu habis karena utang-utangku dan kawan-kawan."

Saidah memperhatikan bibirnya yang membiru dan kedua telapak tangannya yang pucat. Setelah dekat, Saidah mendengar suara keruyuk dari perut Karyamin.

"Makan, Min?"

"Tidak. Beri aku minum saja. Daganganmu sudah ciut seperti itu. Aku tak ingin menambah utang."

"Iya, Min, iya. Tapi kamu lapar, kan?"

Karyamin hanya tersenyum sambil menerima segelas air yang disodorkan oleh Saidah. Ada kehangatan menyapu kerongkongan Karyamin terus ke lambungnya.

"Makan, ya Min? Aku tak tahan melihat orang lapar. Tak usah bayar dulu. Aku sabar menunggu tengkulak datang. Batumu juga belum dibayarnya, kan?" (Tohari, 1989: 4)

Inilah humanisme ala budaya cablaka, Karyamin yang terlihat sangat lesu dan lemas ditawari makanan oleh Saidah. Namun, Karyamin menolak lantaran ia tahu jika dagangan Saidah belum laku, dan lebih sering dihutang oleh kawankawannya. Ia sendiri tidak punya uang untuk membayar makanan dan hutanghutannya. Karyamin hanya meminta air putih. Saidah tak mampu memaksa Karyamin yang jelas sama-sama mengetahui nasib masing-masing.

Dalam cerpen Jasa-jasa Buat Sanwirya (JJBS), estetika profetik tercermin pada tokoh Aku, Sampir, Ranti, Waras dan Nyai Sanwirya.

"Jadi kawan-kawan," kata Sampir, "kita sudah sepakat sama-sama merasa kasihan pada Sanwirya. Begitu?"

Waras menoleh padaku, lalu Ranti.

"Paling tidak itu lebih lumayan daripada bertengkar," kataku (Tohari, 1989: 7).

Cerpen JJBS menarasikan tentang rencana jasa (pertolongan) yang patut diberikan pada Sanwirya. Sanwirya adalah seorang penderes atau penyadap nira kelapa. Ia terjatuh dari pelepah pohon kelapa. Tubuhnya terbanting ke tanah sehingga mengalami luka parah. Keberadaannya sebagai orang desa yang miskin 
sangat memprihatinkan. Para tetangga bahu membahu mencoba memberi bantuan semampunya. Beberapa di antaranya memulainya dengan memusyawarahkan jenis bantuan yang masih memungkinkan diberikan demi keberlangsungan hidup Sanwirya.

"Syukur! Marilah. Ada banyak cara untuk merasa kasihan kepada penderes itu. Menyobek kaus yang sedang kupakai untuk membalut luka Sanwirya adalah sejenis rasa kasihan yang telah kulakukan. Oh, jangan tergesa, kita akan menetukan lebih dulu demi apa rasa kasihan itu kita adakan" (Tohari, 1989: $8)$.

Musyawarah dengan tuturan cablaka mencerminkan kesetaraan stat us warga. Tidak ada perbedaan strata sosial apapun yang dapat dijadikan alasan untuk setuju atau menolak gagasan yang disampaikan. Setiap rencana akan ditanggapi berdasarkan logika sederhana orang desa. Dalam hal ini, sifat cablaka kembali membentuk sikap egaliter yang merupakan manifestasi profetisitas dalam budaya Banyumas.

Perasaan wong cilik yang senasib dan sepenanggungan menjadi bagian tak terpisahkan dari cablaka. Keterusterangan yang dituturkan secara spontan ini telah menjadi perilaku hidup masyarakat Banyumas, terutama saat berkomunikasi dengan sesama orang Banyumas. Ini merupakan nilai paling fondamental dari humanisme dalam khazanah budaya Banyumas.

\section{Sabar dan Menerima}

Sabar lan nrima yaitu sabar dalam menerima segala peristiwa yang dialami dengan apa adanya dalam kehidupan sehari-hari. Sabar semacam ini merupakan puncak keikhlasan yang menandai keimanan seseorang. Ini merupakan bagian dari akhlak ḥabl min Allāh. Sabar merupakan esensi dari perasaan yang paling imanen tentang adanya takdir dari Allah SWT. Sabar menerima cobaan dan ditakdirkan dari Allah ini merupakan estetika profetik ala wong Banyumas. Mereka selalu bersikap dan bertindak sabar dengan kesadaran yang tinggi, ikhlas lahir dan batin dengan segala nasib yang dialami.

Sabar lan nrima merupakan laku, wujud kearifan lokal Banyumas yang dilandasi oleh iman yang teguh. Ini merupakan manifestasi atas pengakuan eksistensi Tuhan sebagai pusat kehidupan. Sabar lan nrima menjadi salah satu inti cerita dan nilai profetis dalam cerpen Si Minem Beranak Bayi (SMBB).

Masih terkesan amat dalam di hati Kasdu bagaimana Minem menyeringai menahan sakit. Bagaimana dia menutup saluran napasnya, kemudian mengerutkan urat-urat perut agar jabang bayi terdorong ke luar. Sesudah bayi kecil itu ke luar, Minem diam tak bergerak. Wajahnya yang begitu pasi basah 
oleh keringat. Minem terus diam. Hanya denyut nadinya yang lemah menandakan dia tidak mati (Tohari, 1989: 14).

Profetisitas tidak muncul secara vulgar dalam bentuk tuturan-tuturan, melainkan mewujud dalam laku dan sikap hidup. Penghayatan hidup yang dalam akan segala hal yang dilakoni. Inilah representasi rasa syukur dan ikhlas yang sederhana. Wong Banyumas menempatkan hubungan hamba dengan Tuhan sebagai sesuatu yang sangat pribadi. Itulah sebabnya urusan-urusan yang berhubungan dengan ritual keagamaan secara pribadi tidak tampil verbal, melainkan menyublim dalam penghayat an terhadap kehidupan, sabar lan nrima.

Dulu ketika Blokeng baru diketahui hamil empat bulan ada seorang hansip yang bertanya kepadanya, siapa ayah si jabang bayi.

"Mbuh," jawab Blokeng.

"Eh, katakan saja demi kebaikanmu sendiri dan demi bayimu yang pasti memerlukan wali bila kawin kelak."

“Mbuh, mbuh-mbuh-mbuh!” (Tohari, 1989: 34-35).

Fragmen dari cerpen Blokeng ini berkisah tentang seorang perempuan tunawisma. Ia hidup dan tinggal menggonggok begitu saja di tempat pembuangan sampah di pasar. Suatu ketika Blokeng diketahui mengandung bayi. Tidak ada yang mengetahui siapa yang telah dengan kejam menghamili perempuan cacat mental dan tunawisma itu. Bahkan, hingga anak lahir ke dunia, tak ada yang mau mengakui sebagai ayahnya. Justru sebaliknya, warga desa merasa perlu menghindar sejauh mungkin, semua menjadi embuh.

Kata 'mbuh' digunakan untuk mengungkapkan kondisi yang sulit digambarkan. Ini merupakan verbalitas paling sederhana dan lugas untuk keadaan apa adanya (nrima ing pandum). Wong Banyumas akan mengatakan ' mbuh' untuk menjawab pertanyaan atau persoalan yang tidak dipahaminya. Kata ' $m b u h$ ' berarti tidak tahu. Dalam khazanah budaya Banyumas, mbuh merepresentasikan sikap tidak mau tahu. Mbuh adalah varian ke-cablaka-an yang dilandasi kesadaran yang dalam tentang penerimaan nasib. Mbuh adalah diksi paling lugas untuk menyatakan nasib, untuk mendesakkan kenyataan ke tengahtengah sebuah keadaan yang tidak menentu. Dengan 'mbuh', wong Banyumas menerima keadaan yang sudah terjadi di luar kehendaknya: liberasi.

.... Suatu pagi Blokeng membawa bayinya ke depan pintu gubuk, dilelo-lelo, ditimang-timang. "Cowet, anakku. Ayahmu itu mbuh. Tetapi jangan sedih ya. Lihatlah orang-orang itu, orang-orang gundul. Lucu ya?” (Tohari, 1989: 37).

Fragmen akhir cerpen Blokeng ini menegaskan sikap wong Banyumas yang marginal pada saat menerima kondisi atau nasib yang dialaminya. Sekali 
'mbuh' tetap 'mbuh'. Artinya, wong Banyumas tidak akan pernah protes tentang suatu keadaan, yang ia sendiri tidak mengerti mengapa hal demikian dapat terjadi, sabar lan nrima dan merdeka secara sosial dan kemanusiaan.

Orang-orang Banyumas memiliki falsafah bahwa hidup itu sandrema nglakoni (hanya tinggal menjalani; ikhlas). Artinya, bagi wong Banyumas hidup dan kehidupan ini adalah narasi yang telah ditentukan oleh Sang narator. Sementara itu, manusia adalah pelakon-pelakon cerita yang berterima dengan berbagai peran yang harus dijalaninya. Ini merupakan bentuk kesadaran tentang makna ikhlas yang paling paripurna, sekaligus liberasi sosial.

\section{Berjiwa Ksatria}

Khazanah budaya Banyumas juga mangenal sikap berjiwa ksatria yaitu jujur, berkepribadian baik dan toleran, rukun suka membantu orang lain, serta mementingkan kepentingan bersama. Mereka berjiwa besar; menerima apa adanya menuturkan apa yang harus dituturkan, berani mengakui dan melakoni kekalahan hidup. Sikap ksatria ditunjukan oleh dua tokoh dalam cerpen $A h$, Jakarta (AJ). Cerpen ini berkisah tentang dua penduduk desa yang sejak kecil saling bersahabat. Satu di antaranya merantau ke Jakarta. Kerasnya hidup di ibukota menempanya menjadi bromocorah. Ia terjun ke kehidupan kelam. Pada suatu malam, ia pulang ke desanya dan berjumpa dengan sahabat di masa kecilnya di desa.

Ia mengaku dalam pelarian, bekerja sebagai gali atau perampok di Jakarta. Ia berhasil lolos dari maut, saat mobil yang ditumpangi usai merampok mengalami kecelakaan. Ia hanya menderita beberapa luka di tubuhnya. Kepada sahabatnya itu, ia berkata terus terang tentang apa yang baru diperbuat dan dialaminya. Ia adalah gali yang dalam pelarian. Bagi wong Banyumas, sahabat tetap sahabat. Apapun kondisinya, seorang sahabat adalah sahabat. Ia tidak akan dianggap musuh, meski kemungkinan ada sebagaian orang yang tengah memusuhinya.

Dia tidak bohong. Apa yang telah diceritakannya termuat sepenuhnya. Dadaku menyesak. Di hadapanku kini duduk seorang karib yang pasti buronan. Aku langsung teringat konsekuensi hukum bagi orang yang menyimpan oknum yang sedang dicari polisi. Tapi detik itu juga kuputuskan menerima karibku seperti biasa, aku tak ingin kehilangan rasa persahabatan. Tidak ingin menyilahkan pergi, apalagi melaporkannya kepada ketua RT (Tohari, 1989: 28).

Wong Banyumas akan melakukan seleksi terhadap berbagai kemungkinan yang dapat terjadi. Ia selalu memiliki pertimbangan yang matang dalam 
menyelesaikan persoalan. Hal ini termasuk bersikap terhadap persoalan yang dihadapi sahabatnya. Jiwa ksatria tampil sebagai penentu tindakan yang akan dilakukan sebagai perwujudan rasa toleransi yang tinggi. Rasa kemanusiaan berada di atas segala-galanya. Kemanusiaan kerap menjadi satu-satunya pertimbangan yang paling masuk akal untuk menentukan sikap. Kemanusiaan ini pula yang menjadi landasan berpikir paling logis bagi wong Banyumas dalam bertindak. Rasa kemanusiaan adalah dasar dari setiap perbuatan yang dapat diterima di mana saja.

Kemudian, pengakuannya berprofesi sebagai gali kepada sahabatnya di desa merupakan cerminan sikap ksatria. Ia berkata jujur bahwa dirinya adalah perampok yang selamat dari kecelakaan. Kejujuran ini pula yang membuat sahabatnya tidak canggung untuk memberikan pertolongan, dengan dasar rasa kemanusiaan. Dari fragmen ini dapat terlihat mengenai jiwa ksatria yang dimiliki wong Banyumas kembali diejawantahkan secara cablaka.

"Ini mayat karibku," kataku kepada dua orang polisi yang sedang mencatatcatat, keduanya terbelalak. Orang-orang pun terbelalak. (Tohari, 1989: 31)

Seminggu setelah pergi tanpa pamit dari rumahnya, si Gali ditemukan tewas dan jasadnya mengambang di bawah jembatan sungai Serayu. Kepada petugas kepolisian dan masyarakat yang menyaksikan penemuan mayat, ia dengan ksatria mengakui bahwa mayat tersebut adalah mayat sahabatnya. Ia menguburkan mayat sahabatnya di tepi sungai.

Berani berterus terang dengan risiko yang tinggi mendapat kerugian merupakan penanda paling gamblang dari jiwa ksatria. Jika bukan lantaran rasa kemanusiaan, maka wong Banyumas tidak akan melakukan tindakan yang penuh risiko. Rasa kemanusiaan menjadi daya bagi tumbuhnya jiwa ksatria. Orang-orang yang telah kehilangan rasa kemanusiaan tidak akan memiliki jiwa ksatria.

\section{Cancudan}

Cancudan atau rajin dan cekatan atau trengginas. Karakter ini merupakan refleksi lanjutan dari toleransi dan gotong-royong sebagai bagian dari jiwa ksatria. Gotong-royong dalam tradisi wong Banyumas tidak akan berlangsung tatkala sikap cancudan ini sudah tidak dimiliki. Cancudan adalah laku yang menandai kesigapan dalam bekerja, keseriusan dan kerja keras. Islam mengajarkan pada umatnya untuk giat bekerja, mencari penghidupan sebagai perwujudan peribadatan yang dilandasi semangat mencari ridha Allah.

Dalam kumpulan cerpen Senyum Karyamin lau cancudan antara lain digambarkan melalui tokoh Karyamin, Kasdu, Kimin, Musgepuk dan tokoh- 
tokoh lain dalam cerpen yang muncul tanpa nama. Tokoh-tokoh ini merepresentasikan karakter cancudan dalam setiap pekerjaan atau profesi yang dijalani.

Karyamin melangkah pelan dan sangat hati-hati. Beban yang menekan pundaknya adalah pikulan yang digantungi dua keranjang batu kali. Jalan tanah yang sedang didakinya sudah licin dibasahi air yang menetes dari tubuh Karyamin dan kawan-kawan, yang pulang balik mengangkat batu dari sungai ke pangkalan material di atas sana. Karyamin sudah berpengalaman agar setiap perjalanannya selamat. Yakni berjalan menanjak sambil menjaga agar titik berat beban dan badannya tetap berada pada telapak kaki kiri atau kanannya. Pemindahan titik berat dari kaki kiri ke kaki kanannya pun harus dilakukan dengan baik. Karyamin harus memperhitungkan tarikan napas serta ayunan tangan demi keseimbangan yang sempurna (Tohari, 1989: 1).

Profesi Karyamin dan kawan-kawan sebagai tukang pengumpul batu-batu kali menjadi citraan karakter wong Banyumas yang cancudan. Untuk memecah dan mengumpulkan batu-batu kali dibutuhkan kerja keras. Ia harus memliki keterampilan yang tinggi. Tidak semua orang mampu melakukannya. Ia harus cekatan. Seorang pemecah batu harus mampu memperhitungkan dengan cepat dan teliti; bagian mana dari permukaan batu yang harus dipukul agar pecah. Tidak asal pecah, melainkan pecah sesuai dengan ukuran yang dikehendaki. Ia juga harus sigap memosisikan dirinya, berdiri pada sudut paling presisi, mencari ruang yang paling aman agar tidak terkena pecahan batu. Pekerjaan ini sangat membutuhkan ketelitian dan kecekatan yang tinggi, cancudan.

Bila bukan karena sebuah tempurung yang tergeletak di tempat itu mungkin aku masih diam. Tetapi karena tempurung itu, aku bisa berbuat sesuatu. Mayat karibku kusirami. Aku memandikannya. Lalat beterbangan. Kemudian dengan tempurung itu pula aku menggali pasir membujur ke utara. Dia kutarik dan kumasukkan ke dalam lubang pasir sedalam lutut. Kusembahyangkan kemudian kumiringkan ke barat. Daun-daun jati kututupkan, lalu pasir kutimbunkan. Sebuah batu sebesar kepala kubuat nisan (Tohari, 1989: 31-32).

Cancudan sebenarnya adalah semangat bekerja dengan memberdayakan berbagai potensi yang ada di sekitarnya. Cancudan mendapatkan bentuknya yang paling jelas tatkala wong Banyumas mampu menyelesaikan pekerjaan dengan piranti seadanya. Cancudan merupakan wujud kearifan lokal yang menjiwai segala sendi kehidupan sosial masyarakat Banyumas. Cancudan adalah sebuah religiositas yang menampak sebagai gerak dan laku.

\section{E. Simultanitas}

Secara keseluruhan, kumpulan cerpen SK menunjukkan estetika profetis dalam satu kesatuan yang utuh (simultanitas) antara empat karakter; cablaka, 
sabar lan nrima, berjiwa ksatria, dan cancudan dengan tiga konsep estetika profetik, yaitu humanisasi (amar ma'rüf), liberasi (nahy munkar) dan transendensi dengan beriman kepada Allah SWT (tu'minūna billāh). Simultanitas semacam ini dibangun melalui plot yang begitu kuat pada cerpen Syukuran Sutabawor, Rumah Yang Terang, Orang-Orang Seberang Kali, Wangon Jatilawang, dan Pengemis dan Shalawat Badar.

Syukuran Sutabawor mengisyaratkan nilai transedensi secara lugas. Cerpen ini mengisahkan persoalan hubungan hamba dengan Allah dalam kultur masyarakat Banyumas yang egaliter. Sutabawor dikisahkan mengadakan syukuran atas panen jengkol yang dialaminya. Sebelum panen, Sutabawor melakukan ritual pemanjatan doa kepada Allah. Kedua peristiwa ini merupakan pengejawantahan nilai transendensi.

Kemudian Rumah Yang Terang, cerpen ini sebenarnya bertutur tentang penghematan dan kesederhanaan hidup sebagai perwujudan rasa syukur atas karunia dari Allah.

"Ayahku memang tidak suka listrik. Beliau punya keyakinan hidup dengan listrik akan mengundang keborosan cahaya. Apabila cahaya dihabiskan semasa hidup maka ayahku khawatir tidak ada lagi cahaya bagi beliau di alam kubur" (Tohari, 1989: 46).

Kutipan ini menunjukan kesadaran yang paripurna tentang hakikat kesederhanaan dan rasa syukur atas nikmat dari Allah SWT. Barang siapa bersyukur maka Allah akan melipatgandakan nikmat.

Pada cerpen Orang-orang Seberang Kali, nilai transedensi bergerak selaras dengan humanisme dan liberasi melalui tokoh saya (aku). Tokoh saya melakonkan sebagai seorang kiyai yang dengan kesadaran kemanusiaanya membimbing tetangganya menghadap sang Khalik melalui fragmen sakaratul maut. Ia digambarkan membimbing Madrakum -tukang sabung ayam yang tengah meniti ajal- dengan membaca surat al-Fatihah, dan mendoakannya. Narasi pendek ini berhasil mengemas tiga kesadaran sekaligus; rasa kemanusiaan yang dalam, liberasi, dan transedensi.

Setali tiga uang, cerpen Wangon Jatilawang, juga mendesakkan tiga kesadaran profetik secara sublim dan subtil. Tokoh aku kembali pembawa pesan tentang pentingnya memanusiakan manusia, membebaskan dari belenggu strata sosial dalam kesadaran menuju ridha Allah. Tokoh aku memberi contoh tentang bagaimana memperlakukan Sulam -tokoh pengemis dan gelandangansecara manusiawi dengan memberi makan dan pakaian serta tempat singgah.

Alegori semacam ini juga muncul pada cerpen Pengemis dan Shawalat Badar. Cerpen ini menyodorkan realitas tentang pengemis yang sering ber- 
operasi di dalam bus dengan melantunkan shalawat sebagai cara menarik kesadaran penumpang untuk menyisihkan sebagain hartanya bagi kaum papa. Humanisme dan transendensi disublimasikan secara subtil sehingga pesan profetik terasa sangat halus.

\section{F. Simpulan}

Estetika profetis dalam khazanah budaya cablaka terbentuk dari karakter (1) cablaka; (2) sabar lan nrima; (3) berjiwa ksatria; dan (4) cancudan. Keempat khazanah budaya Banyumas ini secara simultan merepresentasikan kaidah profetik yang menjadi konsep dasar sastra profetik, yaitu humanisasi (amar ma'rūf), liberasi (nahy munkar) dan transendensi yaitu beriman kepada Allah SWT (tu'minūna billāh).

Nilai humanisasi yang muncul antara lain; pertama, menjaga rasa persaudaraan sesama meski berbeda keyakinan, dan stat us sosial-ekonomi. Kedua, memandang manusia secara total meliputi aspek fisik dan psikisnya, sehingga muncul kehormatan kepada setiap individu. Nilai liberasi yang muncul yaitu memihak kepada kepentingan wong cilik atau orang yang lemah (mustad'afin) seperti petani dan buruh, serta menegakkan keadilan dan kebenaran. Nilai transedensi yang muncul yaitu pengakuan adanya kekuatan supranatural (Allah), mengaitkan perilaku, tindakan, dan kejadian dengan ajaran al-Qur'an dan Hadis, menerima masalah hidup dengan rasa tulus (sabar lan nrimo ing pandum) dan tujuan mendapat ridha Allah.

\section{Daftar Pustaka}

Anwar, Wan. 2007. Kuntowijoyo; Karya dan Dunianya. Jakarta: Grasindo.

Bertes, K. 2007. Etika. Jakarta: PT Gramedia Pustaka Utama.

Hadi. W.M., Abdul. 2004. Hermeneutika, Estetika, dan Religiusitas. Yogyakarta: Matahari.

Herusatoto, Budiono. 2008. Banyumas: Sejarah, Budaya, Bahasa, dan Watak. Yogyakarta: LKiS.

Iqbal, Muhammad. 1966, Pembangunan Kembali Alam Pikiran Islam (The Reconstruction of Religious Thought In Islam), terj. bahasa Osman Raliby. Jakarta: Bulan Bintang.

Kuntowijoyo. 2006. Maklumat Sastra Profetik. Yogyakarta: Grafindo Litera Media. 2013. Maklumat Sastra Profetik. Yogyakarta: Multi Presindo. 
Noor, Acep Zamzam. 2011. Puisi dan Bulu Kuduk. Bandung: Nuansa Cendekia Pradopo, Rachmat Djoko. 2007. Beberapa Teori Sastra, Metode Kritik dan Penerapannya. Yogyakarta: Pustaka Pelajar.

Priyadi, Sugeng. 2007. "Cablaka Sebagai Inti Model Karakter Manusia Banyumas”. Diksi Vol. 14. No.1 Januari 2007.

Ratna, Nyoman Kutha. 2004. Teori, Metode, dan Teknik Penelitian Sastra; Dari Strukturalisme Hingga Posstrukturalisme; Perspektif Wacana Naratif. Yogyakarta: Pustaka Pelajar.

Ricoeur, Paul. 2006. Hermeneutika Ilmu Sosial. Terj: Muhammad Syukri. Yogyakarta: Kreasi Wacana.

Roqib, Muhammad. 2011. Prophetic Education. Purwokerto: STAIN Press.

Sumardjo, Jacob. 1983. Filsafat Seni. Bandung: ITB Bandung.

Teeuw, A. 1983. Tergantung Pada Kata. Jakarta: Pustaka Jaya.

Tohari, Ahmad. 1989. Senyum Karyamin. Jakarta: Gramedia Pustaka Utama. Trianton, Teguh. 2013. Identitas Wong Banyumas. Yogyakarta: Graha Ilmu. Wachid. B.S., Abdul. 2002. Religiositas Alam; dari Surealisme ke Spritualisme D. Zawawi Imron. Yogyakarta: Pustaka Pelajar.

Yudiono K.S. 2003. Ahmad Tohari: Karya dan Dunianya. Jakarta: PT Grasindo. 